\title{
Seasonal Fluctuation of the Pine Wood Nematode, Bursaphelenchus xylophilus (STEINER et BUHRER) NiCKLE (Nematoda: Aphelenchoididae), Transmitted to Pine by the Japanese Pine Sawyer, Monochamus alternatus Hope (Coleoptera: Cerambycidae)
}

\author{
Ei'ichi SHIBATa \\ Nara Forest Experiment Station, Takatori, Nara 635-01, Japan
}

(Received August 16, 1984)

\begin{abstract}
Seasonal fluctuation in numbers of the pine wood nematode, Bursaphelenchus xylophilus (Steiner et Buhrer) NickLe, transmitted to pine from the bodies of adult Japanese pine sawyers, Monochamus alternatus Hope, was determined from the simulation model proposed by Togashi (1980). Nematodes invaded the pine trees between mid-June to late-July, with the peak invasion in late-June. This peak appeared about two weeks after the number of adult beetles reached maximum. In the study forest, pine trees diseased by nematodes appeared before July 20 and 31 trees died before winter began. The date that a cumulative 50 percent of the trees were diseased was August 11, 56 days after a cumulative 50 percent of the nematodes invaded the pine trees.
\end{abstract}

\section{INTRODUCTION}

The pine wood nematode, Bursaphelenchus xylophilus (STEIner et BuHrer) Nickie, the causal agent of pine wilt disease, is transmitted to healthy pine trees by adults of the Japanese pine sawyer, Monochamus alternatus Hope, during their maturation feeding on twigs. An estimate of the number of pine sawyer adults and pine wood nematodes invading the trees would be valuable in predicting the potential number of trees that will be killed by the nematodes. However, seasonal fluctuations in the number of nematodes which are transmitted and invade the trees within an infested pine forest are not yet understood.

In a previous paper (Shibata, 1981), I determined the population size of adult sawyers during their maturation feeding using a combination of the shaking-falling method and a mark-recapture technique in an 8-year old forest of Japanese black pine, Pinus thunbergii PARL, at Kose, Gose City, Nara Prefecture in 1979. The invasion curve of the pine wood nematode transmitted to pine twigs from the bodies of adult beetles which emerged from the caged logs of dead pines in the same forest has also been determined in the laboratory (see Appendix). Using both of the above data, I estimated the seasonal trend in the number of nematodes that invaded these trees by the simulation model proposed by Togashi (1980).

\section{MATERIALS AND METHODS}

Simulation model. Togashi (1980) proposed the following simulation model to esti- 
mate the number of nematodes invading pine trees.

$$
N_{B(t)}=\sum_{x=0}^{t} N_{M} E(t-x) S(x) H N_{B} I(x)
$$

where: $N_{B(t)}$ is the number of nematodes that invaded the trees from adults of the sawyer on $t$-th day of the emergence curve; $N_{M}$ is the total number of sawyer adults that emerged in the forest; $E(t)$ is the ratio of the number of adults that emerged on $t$-th day to $N_{M}\left(\sum_{t=0}^{\infty} E(t)=1\right) ; S(x)$ is the survival rate of adults of the sawyer $x$ days after emergence; $I(x)$ is the ratio of the number of nematodes invading pine trees from sawyer adults $x$ days after emergence to the total number of invading nematodes $\left(\sum_{t=0}^{\infty} I(x)=1\right)$; $H$ is the ratio of the number of sawyer adult bodies holding nematodes to $N_{M}$; and $N_{B}$ is the mean number of invading nematodes to pine trees per adult of the sawyer.

This model is based on the following two assumptions: adults of the sawyer do not immigrate from other pine forests and the emergence pattern of adult beetles in the forest is similar to that determined on the caged logs at the Experiment Station.

Data on adults of the sawyer. $E(t)$ was converted from the emergence curve obtained from the caged logs of trees infested the previous year (Shibata, 1981). $N_{M}$ was calculated by IwAo's (1970) method ${ }^{1}$ based on the estimated population size (Shibata, 1981) $\left(N_{M}=853.9\right)$. Mean survival rate per day $\left(\phi_{m}\right)$ was calculated according to Nakamura and Ohgushi (1979). That is, from the Appendix of Shibata (1981), $\hat{\phi}_{i}$ was given by $\hat{\phi}_{i}=\Phi_{i^{1 / n}}$ at each sampling time $\left(\Phi_{i}\right.$ : the survival rate between $i$ th and $i+1$ th sampling. $n$ : the sampling interval in days) and $\phi_{m}$ was the average of $\hat{\phi}_{i}$. $\phi_{m}$ was 0.860 and survival rate of $x$-day-old adults $\left(S_{x}\right)$ was given by $\phi_{m}{ }^{x}$.

Data on the pine wood nematode. The number of nematodes carried by an adult sawyer newly emerged from a dead pine tree can be estimated as the sum of nematodes successfully invading the pine tree, those failing to invade, and those remaining in the dead body of the adult sawyer (Togashi and Sekizuka, 1982). In this study, $H$ was 1.0 because all adults carried nematodes just after emergence (mean number of nematodes per adult: $1,309.6$; $\max : 10,630 ; \min : 20)$. The mean number of nematodes that successfully invaded the twig per adult beetle $\left(N_{B}\right)$ was 804.1 ( $\left.\max : 8,727 ; \min : 0\right)$. $I(x)$ was converted from the invasion curve of nematodes (see Appendix).

\section{RESULTS AND DISCUSSION}

Figure 1 shows the seasonal fluctuation in the number of pine wood nematodes that invaded the pine trees in the study forest. Nematodes began to invade about June 10 and reached a peak about June 25, after which they gradually decreased. The invasion period was approximately 65 days. In this forest, the number of adult beetles on healthy trees increased in early June and reached a peak in the middle of June (Shibata, 1981). Therefore, the peak of nematode invasion appeared about two weeks after the number of adult beetles reached a peak.

$1 \quad N_{M}=\hat{N}_{2}+\sum_{2}^{11}\left(\hat{B}_{i} / \hat{\phi}^{1 / 2}\right)$

Each symbol is explained in the Appendix of Shibata (1981). 


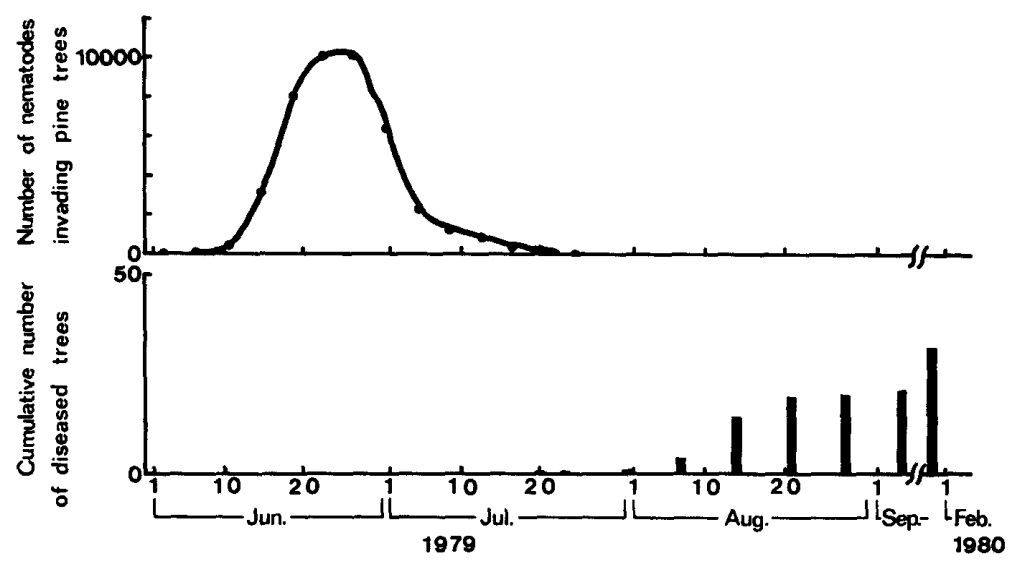

Fig. 1. Seasonal fuctuations in numbers of nematodes transmitted to the pine forest from adults of the pine sawyer and accumulated number of diseased trees.

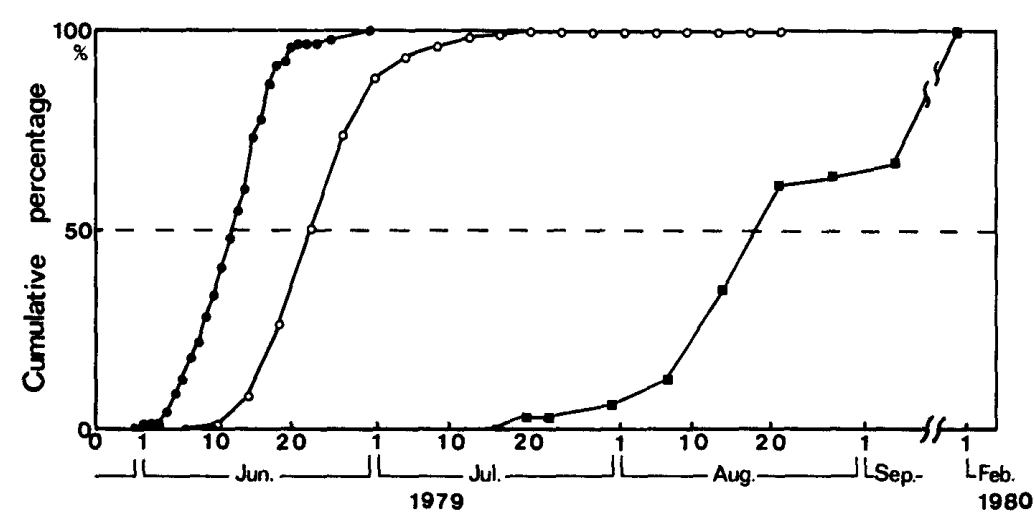

Fig. 2. Cumulative percentages of the number of emerged adult beetles $(\bullet)$, invading nematodes $(O)$ and diseased trees

There was a ten day difference between the date of 50 percent cumulative beetle emergence (June 12) and the date a 50 percent cumulative number of nematodes invaded the pine trees (June 22) (Fig. 2). This period was similar to that observed by Morimoto and IwASAKr (1973).

Of the 97 trees that were healthy at the beginning of this investigation, one had become diseased ${ }^{2}$ before July 20 and then 31 , all of which died before winter, appeared one after another (Fig. 1). The date that a cumulative 50 percent of the trees were diseased was August 11, 56 days after a cumulative 50 percent of the nematodes had invaded the trees (Fig. 2). Adults of the sawyer successfully lay eggs under the bark of diseased trees. As these adults usually fly from late May to late August in this forest (SHibata, 1981), they could presumably lay eggs on as many as 20 trees $(20.6 \%)$ (Fig. 1).

This is the first revelation of the seasonal fluctuation in the number of nematodes invading pine trees, the number of diseased trees caused by nematodes, the number of

2 In this forest, trees diseased (oleoresin flow markedly reduced) or killed (oleoresin flow terminated) by nematodes were counted in every census of adult sawyers. 
adult sawyers emerging from logs, and the number of adult beetles on healthy trees in the same pine forest. TAKETANI et al. (1975) stated that pine wilt disease could appear epidemically when the seasonal occurrence of diseased pine trees, feeding and oviposition of adult sawyers and invasion of the pine wood nematode into pine trees were synchronous. To elucidate why wilt disease has infested the pine forest so quickly and widely in Japan, it is necessary to determine the seasonal invasion of the pine wood nematode to these trees, the feeding and oviposition of adult sawyers and the occurrence of diseased pine trees in many forests as I have done here.

\section{ACKNOWLEDGEMENTS}

I wish to express my sincere thanks to Dr. M. S. MaClure of the Connecticut Agricultural Experiment Station, and Dr. T. Sugrmoto of Kinki University for their invaluable advice and critical reading of this manuscript. Thanks are also due to Mr. K. Togashi of the Ishikawa Forest Experiment Station, and Mr. K. Iто of Kansai Branch, Forestry and Forest Product Research Institute, for their helpful comments on this study.

\section{REFERENCES}

ENDA, N. (1972) Fall-off of the pine wood nematode from the pine sawyer. Proc. 24th Ann. Meet. Kanto Branch Jap. For. Soc. 24: 32 (in Japanese).

Iwao, S. (1970) Dynamics of numbers of a phytophagous lady-beetle, Epilachna vigintioctomaculata, living in patchily distributed habitats. Proc. Adv. Study Inst. Dyn. Number Popul. Oosterbeek, 1970, pp. 129-147.

Kishi, Y. (1978) Invasion of pine trees by Bursaphelenchus lignicolus M. \& K. (Nematoda: Aphelenchoididae) from Monochamus alternatus Hope (Coleoptera: Cerambycidae). J. Jap. For. Soc. 60: 179-182 (in Japanese).

Morimoto, K. and A. Iwasaki (1973) Estimation of the periods needed to prevent the pine sawyer from feeding. Trans. 26th Ann. Meet. Kyushu Branch Jap. For. Soc. 26: 201-202 (in Japanese).

Nakamura, K. and T. Ohgushi (1979) Studies on the population dynamics of a thistle-feeding lady beetle, Henospilachna pustulosa (KôNo) in a cool temperate climax forest. I. The estimation of adult population parameters by the marking, release and recapture method. Res. Popul. Ecol. 20 : 297-314.

Shibata, E. (1981) Seasonal fluctuation and spatial pattern of the adult population of the Japanese pine sawyer, Monochamus alternatus Hope (Coleoptera: Cerambycidae), in young pine forest. Appl. Ent. Zool. 16: 306-309.

Taketani, A., M. Okuda and R. Hosoda (1975) The meteorological analysis on the epidemic mortality of pine trees, with special reference to the effective accumulated temperature. J.Jap. For. Soc. 57: 169- 175 (in Japanese with an English summary).

Togashi, K. (1980) A simulation model for the optimal time for utilizing insecticide spray against the Japanese pine sawyer, Monochamus alternatus Hope (Coleoptera: Cerambycidae). J. Jap. For. Soc. 62: 381-387 (in Japanese with an English summary).

Togashi, K. and H. Sekizuka (1982) Influence of the pine wood nematode, Bursaphelenchus lignicolus (Nematoda: Aphelenchoididae), on longevity of its vector, Monochamus alternatus (Coleoptera: Cerambycidae). Appl. Ent. Zool. 17: 160-165.

\section{APPENDIX}

To determine the invasion curve of the pine wood nematode, 15 female and 15 male adults of the pine sawyer collected within one day after their emergence from the caged logs of dead pine trees in 1979 were 


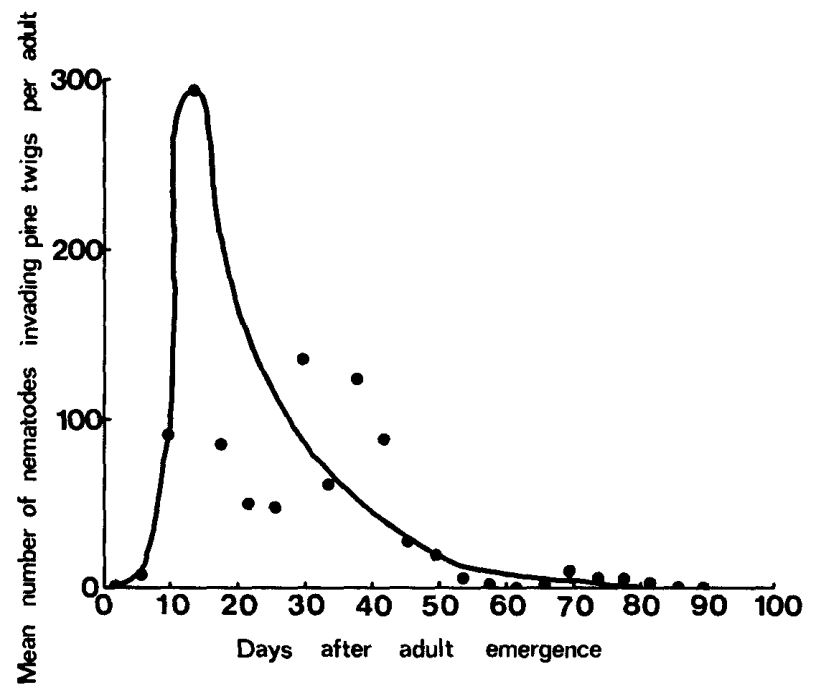

Figure in Appendix. Invasion curve of the pine wood nematode on pine twigs in the laboratory.

examined according to KIsHI (1978): each adult was kept in the type of container and under the room conditions described by KIsHI (1978) and was supplied every four days with a 2 or 3-year-old, $10 \mathrm{~cm}$ long twig of $P$. densiflora SIEB. for maturation feeding. Using the BAERMANN funnel technique, nematodes that succeeded in invading the twigs and that remained on the surface of the twigs or containers were extracted and counted when each twig was replaced. Dead adults were dissected and nematodes remaining in each body were counted by the same technique. The figure shows the invasion curve of nematodes transmitted from the adult body to the pine twigs, having peak invasion two weeks after adult beetle emergence. This curve was similar to that reported by ENDA (1972), but not to that reported by KISHI (1978) which had peak invasion just after adult beetle emergence. 